\title{
Walking as a feasible means of effecting positive changes in BMI, waist, and blood pressure in black South African women
}

\author{
Philippe Jean-Luc Gradidge, Precious Nkhensani Golele
}

Centre for Exercise Science and Sports Medicine, Faculty of Health Sciences, University of the Witwatersrand, Johannesburg, South Africa.

\begin{abstract}
Background: In the context of a growing obesity pandemic in sub-Saharan African countries little is known on how to address the problem / disease in the region.

Methods: A randomised controlled trial of walking to decrease obesity was conducted using 115 women employed at the University of Venda, Limpopo province. 49 of these participants were randomly selected into an intervention group, which walked for 30 minutes, 3 days per week for a period of 12 weeks on treadmills located in the university gym. The control group were instructed to continue with usual activities. Baseline and follow-up body mass index (BMI), waist circumference, blood pressure (BP), body size discrepancy (measured by a feel-minus-ideal (FID) index), and physical activity were collected on all participants. Results: The absolute changes in BMI, waist, systolic and diastolic BP in the intervention group was $-0.80,-1.50,-4.02$ and -2.37 , respectively. In contrast, the absolute changes for these were $+1.05,+1.73,+4.64$ and +4.94 , respectively in the control group. The results of the FID analysis showed that most had a desire for thinness.

Conclusion: Our data demonstrates that positive changes in BMI, waist, and BP were observed in the intervention group, indicating the potential scalability of the intervention.

Keywords: Exercise, blood pressure, obesity, intervention.

DOI: https://dx.doi.org/10.4314/ahs.v18i4.10

Cite as: Gradidge P J-L, Golele PN. Walking as a feasible means of effecting positive changes in BMI, waist, and blood pressure in black South African women. Afri Health Sci. 2018;18(4): 917-921. https:// dx.doi.org/10.4314/abs.v18i4.10
\end{abstract}

\section{Introduction}

The obesity pandemic continues to increase in developing low and middle income and sub-Saharan African (SSA) countries, while in more affluent countries the prevalence of obesity seems to have attenuated. ${ }^{1}$ Women are noticeably more affected than men, and in the SSA region, Black South African women appear to have the highest prevalence of obesity. ${ }^{2}$ Consequently, obesity-related non-communicable diseases (NCD) such as chronic elevated blood pressure are increasing in this group. ${ }^{3,4}$

\section{Corresponding author:}

Philippe Jean-Luc Gradidge, Centre for Exercise Science and Sports Medicine, Faculty of Health Sciences, University of the Witwatersrand, Johannesburg, South Africa

Email: philippe.gradidge@wits.ac.za
A study of Black South African women living in Soweto suggests that risk factors for elevated blood pressure and other NCDs are driven by the obesity crisis. ${ }^{5}$ Other countries in the SSA region are experiencing similar increases in obesity-related diseases, symbolic of countries moving through an epidemiological and nutrition transition. ${ }^{4}$ South Africa, like most SSA countries, is experiencing rapid urbanisation, with those migrating to urban centres adopting lifestyle behaviours such as sedentariness and increased consumption of processed foods are acknowledged to be associated with obesity. ${ }^{6}$ Context-appropriate strategies are still needed to address obesity and the increasing risk of related NCDs.

In low resource settings such as South Africa, access to behaviour change strategies is very limited, indicating the need for more feasible solutions. A systematic review on the health benefits of active travel conducted in developed countries has shown that walking can significantly

(C) 2018 Gradidge et al. Licensee African Health Sciences. This is an Open Access article distributed under the terms of the Creative commons Attribution License (https://creativecommons.org/licenses/BY/4.0), which permits unrestricted use, distribution, and reproduction in any medium, provided the original work is properly cited. 
improve cardiorespiratory fitness and lower body mass index $(\mathrm{BMI}){ }^{7}$ The main aim of this study was therefore to determine if an intervention of walking, a primary form of physical activity amongst African populations, could influence the body composition and blood pressure of a cohort of African women employed at a rural-based South African university. ${ }^{8}$ A second aim was to determine whether this walking intervention could influence body size perception of the cohort as evidence suggests acculturation towards leanness amongst African women.

\section{Methods}

This randomized control trial was conducted at the University of Venda, located in the Limpopo province, South Africa. Permission to conduct the study was given by the Human Research Ethics Committee (medical), University of the Witwatersrand (ethics certificate number: M160518). The initial screening included 394 eligible women, aged $\geq 18$ years and employed at the university, 132 of women signed a written consent and agreed to volunteer to participate in the study. Pregnant, illiterate or injured women were not included in this study.

The list of recruited women were given to research assistants to conduct distance randomisation of participants into a control $(n=66)$ and intervention group $(n=66)$. Thus, the researchers were blinded to the assignment sequence, as the research assistances allocated the participants into either the intervention or control group. ${ }^{10}$

The intervention group underwent a 12-week, supervised walking programme, 3 days/week, and 30 minutes per exercise session, during the common lunch-time period to avoid disrupting usual work activities. The control group did not receive any treatment during the 12 week trial period.

\section{Socioeconomic status}

A self-reported questionnaire was used to determine education status (completion of high school, work-type (academic, administrative, or other (e.g. maintenance, security guard, cleaner, and healthcare). Monthly income was also self-reported. Using an accepted measure of socioeconomic status (SES), individual ownership of household assets was used as the primary measure of SES. ${ }^{11}$ These included ownership of the following 11 assets, ranked according to value: (11) motor vehicle, (10) satellite television, (9) electricity, (8) internet subscription, (7) mobile phone, (6) telephone, (5) television, (4) washing machine,
(3) refrigerator, (2) computer/laptop, (1) radio. A total SES score was generated from these household assets by adding the scores from the 11 items to determine a score out of 66 .

\section{Measurements}

Body mass was measured using a digital scale to the nearest $0.01 \mathrm{~kg}$ (Seca, Hamburg, Germany). Stature was measured using a stadiometer (PHR, USA) to the nearest $\mathrm{cm}$. Body mass index (BMI) was calculated as weight $(\mathrm{kg}) /$ height $(\mathrm{m})^{2}$. Waist and hip circumference $(\mathrm{cm})$ were measured while standing, arms at the sides, feet together and abdomen relaxed. Waist-to-Height ratio was calculated. Systolic and diastolic blood pressure (BP) was measured on the right arm with the participant in a seated position using the Omron BP monitor (M6, Europe). The average of the latter two of three measurements was recorded after the participants had rested for at least 10 minutes.

The Global Physical Activity Questionnaire (GPAQ) was used to determine moderate-to-vigorous physical activity (MVPA) and estimated sedentary behaviour (or sitting time). The GPAQ has been previously validated for use in the South African context. ${ }^{12}$ Body size dissatisfaction was determined using a validated tool with nine silhouettes reflecting underweight to morbid obese African women. Participants were asked to point out the image that most closely matched how they perceived themselves, followed by a request to show their ideal body silhouette. A 'feel' minus 'ideal' score was determined using these scores, with a negative score indicating a desire for a larger body size, a positive score signifying a desire to be thinner, and a zero score illustrating that participants were content with their body size. These outcomes were measured in the participants at baseline and follow-up.

\section{Walking intervention}

The participants in the intervention group were required to attend the walking programme on a weekly basis from 09 January to 31 March 2017. The nature of programme was based on previous evidence highlighting that walking is common amongst African populations and adds more to accumulated weekly MVPA than occupation- and recreation-related physical activity. ${ }^{5}$ Using treadmills (Jkexer Sprint 9875A), the walking intervention took place during lunch breaks at the Human Movement Sciences gymnasium, University of Venda. Further, given the limited time 
for lunch breaks ( $\leq 1$ hour), a duration of 30 minutes was agreed upon by the authorities of the university and the participants in order to provide ample time to reach the venue and change into appropriate clothing. Participants' resting BPs were measured on arrival followed by a period of light stretching before starting the 30 minute walking programme. A moderate intensity was ensured by walking speed ( 5 to $5.5 \mathrm{~km} / \mathrm{h}$ ), rating of perceived exertion score of 4 to $8 / 10$, and gradient (0.5 -1.5 degrees) throughout the intervention. The participants were monitored throughout the activity for any exaggerated physiological changes (including increasing angina, drop in systolic BP $>10 \mathrm{~mm} \mathrm{Hg}$ from baseline, fatigue, dyspnea, wheezing, leg cramps) by qualified research assistants. Hydration with water was encouraged and the ambient room temperature was kept at 18 degrees Celsius.

\section{Statistical analysis}

Data was analysed using Stata 14 (StataCorp, USA). The Shapiro-Wilks test was used to test for normality in the continuous variables. Paired t-tests or Wilcoxon matched pairs tests were used to determine intra-group differences between baseline and follow-up anthropometry (BMI, waist and hip circumference, and WHtR), BP (systolic and diastolic BP), and MVPA and sitting time. Inter-group differences in anthropometry, BP, MVPA, and sitting time were tested using Independent t-tests or Mann-Whitney U-tests. Using the pre-test blood pressure and anthropometric measures as covariates, analysis of covariance (ANCOVA) was used to determine the differences in absolute changes of BMI, waist, and BP between the control group and intervention group.

\section{Results}

The participants who dropped out of the intervention group ( $\mathrm{n}=17)$ during the study The final sample included 115 (49; 42.6\% intervention group) participants, with the mean age of the women in the control group being younger than those in the intervention group $(44.4 \pm 11.5$ and $37.4 \pm 8.78$ years respectively, $\mathrm{p}=0.0003$ ). Most of the of the study population were in the moderate socio-demographic stratum as reflected by the SES score, ranging from 17 to $66,47.4 \pm 12.7$ in control group and 47.6 \pm 13.9 in the intervention group, respectively. The occupation types included academics (45.5\% vs $36.7 \%$, control vs intervention groups), administrative roles $(30.3 \%$ vs $28.6 \%$ ), and a group composed of security, maintenance, cleaning, and healthcare staff members $(24.2 \%$ vs $34.7 \%$ ). At baseline $83.3 \%$ of the control group wanted to be leaner compared with $83.7 \%$ in the intervention group, $\mathrm{p}=0.96 ; 4.6 \%$ of the control group were content with body size compared with $12.2 \%$ of the intervention group, $\mathrm{p}=0.13$; and $12.1 \%$ of the control group wanted to have a larger body size compared with $4.08 \%$ of the intervention group, $\mathrm{p}=0.13$. The follow-up body size dissatisfaction scores in the control and intervention group were as follows: wanted to be leaner: $87.9 \%$ vs $83.7 \%$, $\mathrm{p}=0.52$; content with body size: $4.6 \%$ versus $12.2 \%$, $\mathrm{p}=0.13$; and wanted to have a larger body size: $7.58 \%$ vs $4.08 \%, \mathrm{p}=0.13$. Table 1 shows that differences between the control group and intervention group were observed for baseline and follow-up MVPA and sitting time, and only follow-up systolic BP, diastolic BP. The absolute changes for BMI, waist, systolic and diastolic BP of the intervention group were significantly lower in the control group compared with the intervention group. The BMI and waist of the control group increased (+1.10and +1.80 , respectively), and decreased in the intervention group (-0.80 and -1.50 , for BMI and waist, respectively). The systolic and diastolic BP of the intervention group decreased (-4.00 and -2.40 , respectively), and increased in the control group $(+5.00$ and +5.00 , for systolic and diastolic BP respectively). The increase in MVPA was higher in the intervention group compared with the control group ( +165 vs -3.5 , respectively). The sitting time of the control group was increased by 120 mins/day, while no change in sitting time was observed in the intervention group. 
Table 1. Baseline and change characteristics of participants in the control $(n=66)$ and intervention $(n=49)$ groups

\begin{tabular}{|c|c|c|c|c|c|c|}
\hline Variables & Controlgroup $^{b}$ & $\begin{array}{l}\text { Interventio } \\
\text { n group }^{b}\end{array}$ & p-value & $\begin{array}{l}\text { Control } \\
\text { group }\end{array}$ & $\begin{array}{l}\text { Interventi } \\
\text { on group }\end{array}$ & p-value $e^{T}$ \\
\hline $\begin{array}{c}\text { Anthropometry } \\
\text { Weight (kg) }\end{array}$ & $81.9 \pm 17.7$ & $84.6 \pm 17.8$ & 0.26 & $85.9 \pm 20.7$ & $83.8 \pm 20.2$ & 0.83 \\
\hline BMI $\left(\mathrm{kg} \cdot \mathrm{m}^{-2}\right)$ & $31 \pm 6.57$ & $32.1 \pm 6.61$ & 0.18 & $32.8 \pm 7.25$ & $32 \pm 7.03$ & 0.95 \\
\hline WC (cm) & $94.7 \pm 17$ & $96.5 \pm 17.2$ & 0.78 & $93.8 \pm 16.5$ & $92.3 \pm 16.2$ & 0.20 \\
\hline Hip (cm) & $113 \pm 14$ & $115 \pm 14.2$ & 0.39 & $115 \pm 14$ & $115 \pm 11.3$ & 0.50 \\
\hline $\begin{array}{r}\text { WHtR } \\
\text { Blood pressure }\end{array}$ & $58.4 \pm 10.6$ & $59.4 \pm 10.7$ & 0.86 & $58 \pm 9.75$ & $57.1 \pm 9.59$ & 0.13 \\
\hline $\begin{array}{l}\text { Systolic } \\
(\mathrm{mmHg})\end{array}$ & $122 \pm 15.6$ & $127 \pm 14.7$ & 0.17 & $118 \pm 17.5$ & $114 \pm 17.2$ & $<0.0001$ \\
\hline $\begin{array}{l}\text { MAP } \\
\text { (mmHg) }\end{array}$ & $91.3 \pm 11.2$ & $96.1 \pm 10.9$ & 0.28 & $88.7 \pm 13.4$ & $85.8 \pm 12.8$ & $<0.0001$ \\
\hline PP (mmHg) & $46.6 \pm 11.7$ & $46.3 \pm 11.3$ & 0.23 & $44.0 \pm 11.7$ & $42.3 \pm 12$ & 0.07 \\
\hline $\begin{array}{l}\text { Physical activity } \\
\text { Total MVPA } \\
\text { (mins/week) }\end{array}$ & $20(10-40)$ & $16.5(10-30)$ & $<0.0001$ & $45(20,130)$ & $210(195-240)$ & $<0.0001$ \\
\hline $\begin{array}{l}\text { Sitting time } \\
\text { (mins/day) }\end{array}$ & $480(420-600)$ & $\begin{array}{l}600 \quad(480- \\
660)\end{array}$ & $<0.0001$ & $\begin{array}{l}360 \quad(240, \\
480)\end{array}$ & $360(240-480)$ & $<0.0001$ \\
\hline
\end{tabular}

Data presented as mean \pm SD or median (interquartile range) or percent; ${ }^{b}$ Baseline; ( Mean difference; ${ }^{\mathrm{q}}$ Independent t-tests; BMI: body mass index; BP: blood pressure; MAP: mean arterial pressure; PP: partial pressure; MVPA: moderate-to-vigorous physical activity; WC: waist circumference; WHtR: Waist-to-Height ratio

\section{Discussion}

The main finding of this experimental study was that those women who engaged in the 12-week supervised walking programme had lowered BMI and waist circumference, in addition to experiencing decreased blood pressure. In comparison, the women in the control group experienced increases in blood pressure and anthropometry, possibly due to acute changes in eating behaviour and stress. ${ }^{13}$ The sitting time of both groups did not change during the study, however the MVPA of the intervention group increased significantly, which is a likely consequence of involvement in the walking intervention. Future studies need to determine the sustainability of walking programmes amongst African women.

The body size dissatisfaction findings support those of other studies which show that the majority of contemporary African women want to be thinner, ${ }^{9}$ as opposed to earlier studies showing that populations were more attuned to favouring larger body frames. This suggests the readiness of employed African women for accepting strategies to improve body weight.

Further, our data supports the idea that the required phys- ical activity for optimal health outcomes and the prevention of early cardiometabolic morbidity can be attained through a lifestyle of structured walking performed at moderate pace by using the broadly accepted rating of perceived exertion scale. ${ }^{14}$

Strengths of this study include using a feasible intervention to address obesity and elevated blood pressure in employed African women. A limitation of the study ${ }^{15}$ includes the use of self-report questionnaires for physical activity, however, given the limited access to objective measurement tools, validated tools will continue to be utilised in the SSA region. ' A convenient sample of female university employees who had free access to the gym and exercise equipment may limit the generalizability of the study findings. Menopausal status was not determined in this study, thus restricting the comparison of BMI, waist circumference and BP across peri- and post-menopausal women.

In African women experiencing acculturation toward thinness, walking for exercise is an effective tool for lowering BMI, waist circumference, and lowering blood pres- 
sure in employed African women. Further study is needed to investigate whether the walking programme used in this study is sustainable and scalable in the midst of epidemiological transition in SSA countries.

\section{Conflict of interest}

The authors do not have any conflicts of interest.

\section{Author contributions}

Philippe Jean-Luc Gradidge wrote the paper, analysed the data, and was the senior researcher.. Precious Nkhensani Golele collected the data. Both authors were responsible for the conceptual design, and read and accepted the final version of the paper.

\section{References}

1.Ng M, Fleming T, Robinson M, et al. Global, regional, and national prevalence of overweight and obesity in children and adults during 1980-2013: a systematic analysis for the Global Burden of Disease Study 2013. Lancet. 2014;384(9945):766-781.

2. NCD Risk Factor Collaboration (NCD-RisC) - Africa Working Group. Trends in obesity and diabetes across Africa from 1980 to 2014: an analysis of pooled population-based studies. Int J Epidemiol. 2017;46(5):1421-1432.

3. Mensah GA, Mayosi BM. The 2011 United Nations high-level meeting on non-communicable diseases: the Africa agenda calls for a 5-by-5 approach. S Afr Med J. 2012;103(2):77-79.

4. Nojilana B, Bradshaw D, Pillay-van Wyk V, et al. Persistent burden from non-communicable diseases in South Africa needs strong action. S Afr Med J. 2016;106(5):2324.

5. Gradidge PJ, Crowther NJ, Chirwa ED, Norris SA, Micklesfield LK. Patterns, levels and correlates of self-reported physical activity in urban Soweto women. BMC Public Health. 2014;14(934).
6. Micklesfield LK, Lambert EV, Hume DJ, et al. Socio-cultural, environmental and behavioural determinants of obesity in black South African women. Cardiovascular Journal of Africa. 2013:online publication.

7. Saunders LE, Green JM, Petticrew MP, Steinbach R, Roberts H. What Are the Health Benefits of Active Travel? A Systematic Review of Trials and Cohort Studies. PLoS One. 2013;8(8):e69912.

8. Shisana O, Labadarios D, Rehle T, et al. South African National Health and Nutrition Examination Survey (SANHANES-1). Cape Town: HSRC Press; 2013.

9. Gradidge PJ, Norris SA, Micklesfield LK, Crowther NJ. The role of lifestyle and psycho-social factors in predicting changes in body composition in black South African Women. PLoS One. 2015;10(7):e013291.

10. Torgerson DJ, Roberts C. Randomisation methods: concealment. BMJ. 1999;319:375-376.

11. Griffiths PL, Rousham EK, Norris SA, Pettifor JM, Cameron N. Socio-economic status and body composition outcomes in urban South African children. Arch Dis Child. 2008;93(10):862-867.

12. Bull FC, Maslin TS, Armstrong T. Global Physical Activity Questionnaire (GPAQ): Nine Country Reliability and Validity Study. Journal of Physical Activity and Health. 2009;6:790-804.

13. Torres SJ, Nowson CA. Relationship between stress, eating behavior, and obesity. Nutrition. 2007;23(1112):887-894.

14. Laverty AA, Palladino R, Lee JT, C. M. Associations between active travel and weight, blood pressure and diabetes in six middle income countries: a cross-sectional study in older adults. Int J Behav Nutr Phys Act. 2015;12:65. 15. Williams P, Lord SR. Effects of group exercise on cognitive functioning and mood in older women. Aust $N$ Z J Public Health. 1997;21(1):45-52. 